\title{
Mawas diri berideologi: Tantangan berpartisipasi religius online di era ujaran kebencian
}

\author{
Nuri Sadida* \& Thessa Aulin Pratiwi \\ Fakultas Psikologi, Universitas YARSI, Jakarta Pusat, DKI Jakarta
}

\begin{abstract}
Abstrak
Ujaran kebencian di dunia maya merupakan perilaku yang dimotivasi untuk mengekspresikan prasangka. Penelitian sebelumnya menunjukkan bahwa perilaku religius merupakan salah satu faktor yang dapat mendorong ekspresi prasangka. Namun, penelitian sebelumnya saling bertolak belakang dalam mengungkap peran religiusitas dan prasangka, serta ditemukan bahwa kepribadian otoritarianisme seringkali memediasi hubungan tersebut. Penelitian ini berupaya untuk melihat hubungan perilaku religius di dunia maya dengan motivasi ekspresi prasangka, khususnya di media sosial. Lebih lanjut, penelitian ini berupaya untuk memahami faktor yang bisa menjelaskan hubungan antara perilaku religius di dunia maya dan motivasi ekspresi prasangka dengan melihat peran mediasi ideologi otoritarianisme. Penelitian ini menggunakan pendekatan kuantitatif dengan jumlah partisipan 152 orang. Hasil penelitian menunjukkan bahwa keterlibatan dalam aktivitas religius secara online berhubungan langsung dengan motivasi eksternal ekspresi prasangka, dan tidak memiliki hubungan secara langsung dengan motivasi internal ekspresi prasangka. Namun demikian, ditemukan adanya efek tidak langsung pada motivasi internal ekspresi prasangka, melalui ideologi otoritarianisme.
\end{abstract}

Kata kunci: ideologi otoritarianisme, keterlibatan dalam aktivitas religius online, motivasi mengekspresikan prasangka

\begin{abstract}
Cyberhate is a behavior that motivated by the need to express prejudice. Previous literature suggested that religiosity is one of the main factors that encourage prejudice expression. However, it was identified that the relations between religiosity and prejudice have inconsistent findings, and authoritarianism personality was the most significant variable that mediates the relationship. The purpose of current research is to test the relationship between online religious involvement and motivation to express prejudice, particularly in social media settings. Moreover, current research tries to explore the factors that influence the relationship and testing authoritarianism as a mediator variable. This research used a quantitative approach with a total of 152 participants involved in the study. The findings showed that online religious involvement directly related to external motivation to express prejudice, and did not relate significantly with internal motivation to express prejudice. However, there is an indirect relation between online religious involvement and motivation to express prejudice that was mediated by authoritarianism.
\end{abstract}

Keywords: Authoritarianism, motivation to express prejudice, online religious involvement

\section{Pendahuluan}

Seiring dengan meningkatnya penggunaan media sosial di Indonesia saat ini, semakin marak pula persebaran berita bohong dan ujaran kebencian yang menggunakan isu-isu suku, agama, ras, dan antargolongan (SARA) (JakartaPost, 2017). Ujaran kebencian adalah segala bentuk ungkapan yang digunakan untuk memosisikan orang lain secara negatif berdasarkan karakteristik, seperti ras, etnis, agama, jenis kelamin, orientasi seksual, disabilitas fisik dan mental yang dapat menimbulkan kebencian dan memancing kekerasan (Yar, 2013).
Maraknya isu-isu SARA dalam ujaran kebencian pada lalu lintas media sosial di Indonesia mengindikasikan tingginya motivasi untuk mengekspresikan prasangka di media sosial karena ujaran kebencian adalah perilaku yang dimotivasi mengekspresikan prasangka (Hall, 2013).

Hal yang mendorong prasangka termanifestasikan menjadi ekspresi prasangka diklasifikasikan oleh Crandall dan Eshleman (2004) menjadi enam kategori, antara lain, religiusitas. Berbagai penelitian telah banyak melihat hubungan antara religiusitas dan prasangka; menghasilkan temuan yang berbeda-beda akan efek religiusitas terhadap terbentuknya prasangka.

* Fakutas Psikologi, Universitas YARSI 
Temuan Hoffarth, Hodson, dan Molnar (2018) menyebutkan bahwa terdapat hubungan antara tingkat partisipasi dalam aktivitas religius dengan terbentuknya prasangka secara spesifik pada terbentuknya bias antihomoseksual. Sejumlah penelitian juga menunjukkan hasil serupa, seperti penelitian Johnson, Rowatt, dan LaBouff (2010) yang mengemukakan bahwa mengaktivasi konsep religius pada seseorang dapat meningkatkan sikap prasangka seseorang tersebut pada orang lain. Begitu juga dengan penelitian Johnson, Rowatt, dan Labouff (2012) yang menghasilkan bahwa priming materi agama dapat mengakibatkan meningkatnya penolakan terhadap orangorang yang dianggap out-group dan meningkatkan favoritisme terhadap in-group.

Brambilla, Manzi, Regalia, dan Verkuyten (2013) berargumen bahwa korelasi antara religiusitas dan ekspresi prasangka mengindikasikan terdapat variabel yang memediasi hubungan kedua variabel ini. Salah satu variabel yang cukup konsisten ditemukan memediasi hubungan antara kedua variabel ini ialah otoritarianisme. Beberapa penelitian menyebutkan variabel otoritarianisme merupakan variabel yang cukup konsisten dalam memprediksi prasangka terhadap outgroup, terutama bila dikaitkan dengan religiusitas (Laythe, Finkel, \& Kirkpatrick, 2001; Tsang \& Rowatt, 2007).

Namun demikian, dalam penelitian yang dilakukan oleh Bilewicz, Soral, Marchlewska, dan Winiewski (2017) tentang otoritarianisme, disebutkan bahwa seseorang dengan otoritarianisme di dunia maya memiliki sikap negatif atau tidak mendukung ekspresi prasangka dalam bentuk ujaran kebencian. Oleh karena itu, penelitian ini bertujuan untuk melihat apakah ideologi otoritarianisme memediasi hubungan antara keterlibatan dalam aktivitas religius secara online dengan motivasi mengekspresikan prasangka di media sosial.

Sebelum menjelaskan lebih jauh hipotesis penelitian ini, berikut akan diuraikan terlebih dahulu hasil penelitian sebelumnya terkait perilaku religius, ideologi otoritarianisme, dan motivasi ekspresi prasangka.

\section{Keterlibatan dalam aktivitas religius secara online dan motivasi mengekspresikan pra- sangka}

Penelitian sebelumnya tentang aktivitas religius di dunia maya masih sangat terbatas, menyebabkan penelitian yang melihat hubungan antara keterlibatan dalam aktivitas religius di dunia maya dan motivasi mengekspresikan prasangka juga terbatas. Dengan demikian, penelitian ini lebih banyak menelusuri literatur tentang hubungan religiusitas dan prasangka dalam ke- hidupan sehari-hari dengan mempertimbangkan bahwa partisipasi religius seseorang di kehidupan sehari-hari memiliki korelasi yang kuat dengan partisipasi religius di dunia maya. Hal ini disimpulkan dari penelitian yang dilakukan oleh Rahman, Hashim, dan Mustafa (2015) yang menjelaskan bahwa terdapat korelasi yang tinggi antara aktivitas religius di dunia maya dengan aktivitas religius sehari-hari. Kesimpulan ini senada dengan hasil survei dari Pew Research Center (2014) yang menjelaskan bahwa orang yang rajin hadir ke tempat ibadah menunjukkan partisipasi yang tinggi juga dalam aktivitas religius di dunia maya.

Pada penelitian yang dilakukan BurchBrown dan Baker (2016), partisipasi dalam aktivitas religius dapat meningkatkan atau menurunkan tingkat prasangka individu. Perbedaan pengaruh ini dipengaruhi oleh sejauh mana individu mempelajari values, keyakinan, sikap, dan praktik ajaran agama dari lingkungan atau komunitas religiusnya. Apabila komunitas religius seseorang di dunia maya menanamkan sikap, melalui penyebaran informasi agama, bahwa berprasangka terhadap out-group diperbolehkan, maka seseorang tersebut akan mengadopsi sikap atau nilai yang mendukung prasangka.

Lebih lanjut, paparan tipe materi agama tertentu (religion priming) dapat memengaruhi kognisi dan perilaku seseorang tanpa disadari individu tersebut. Terpapar materi agama tertentu dapat membentuk perilaku positif (seperti perilaku prososial), dan perilaku negatif (seperti agresivitas). Pada penelitian Johnson (2017), terdapat perbedaan tingkat agresivitas pada individu yang terpapar konsep kemuliaan/imbalan (good priming) dan hukuman (bad priming) dari materi agama. Individu memiliki tingkat agresi yang rendah ketika terpapar oleh konsep hukuman (bad priming) sementara individu memiliki tingkat agresi yang lebih tinggi ketika lebih banyak mengenali konsep kemuliaan/imbalan (good priming). Sementara, pada penelitian Ramsay, Pang, Shen, dan Rowatt (2013), terbukti bahwa adanya priming religius in-group dapat meningkatkan prasangka di antara pemeluk agama Kristen dan Buddha pada siswa Singapore University. Lebih lanjut, penelitian ini menjelaskan bahwa agama dapat menimbulkan prasangka secara tidak langsung melalui aktivasi nilai tertentu, seperti tradisionalisme atau konservatisme.

Selain itu, mekanisme terbentuknya hubungan antara religiusitas dan prasangka juga dijelaskan oleh Pasek dan Cook (2017). Ketika individu merasakan identitas religiusnya terancam, di mana ancaman ini dapat diperoleh ketika terpapar oleh informasi ujaran kebencian bernuansa SARA di jejaring sosial dunia maya yang marak di media sosial, maka seseorang merasa- 
kan peningkatan prasangka terhadap individu atau kelompok lain. Penelitian tersebut menyimpulkan terdapat faktor persepsi akan identitas religius terancam (religious perceived threat) yang menyebabkan seseorang berprasangka. Dari paparan tersebut, dapat disimpulkan mekanisme psikologis yang menjelaskan hubungan antara partisipasi dalam aktivitas religius dan terbentuknya prasangka adalah adanya adopsi values, keyakinan, dan norma tentang prasangka yang pembentukannya dipengaruhi oleh komunitas religius, paparan tipe materi agama (religious priming), serta perasaan identitas religius yang terancam (religious identity threat).

Motivasi untuk mengekspresikan prasangka, menurut Forscher, Cox, Graetz, dan Devine (2015), dapat dipengaruhi oleh faktor internal (internal motivation to express prejudice) yang bersumber dari dalam diri seseorang dan bersumber dari eksternal diri (external motivation to express prejudice). Sumber faktor internal maupun eksternal dapat berupa pemikiran, values, belief, dan/atau perasaan akan perilaku untuk mengekspresikan prasangka. Motivasi internal (IMP) merefleksikan alasan personal dan didorong oleh pemikiran, values, belief, dan perasaan yang bersumber dari dalam diri seseorang yang membolehkan ekspresi prasangka terhadap kelompok yang tidak disukai. Sedangkan, motivasi eksternal (EMP) menekankan dorongan berupa pemikiran, values, belief, dan perasaan yang membolehkan ekspresi prasangka yang bersumber dari luar diri individu.

Dikaitkan dengan paparan sebelumnya, saat ini banyak materi ujaran kebencian bernuansa SARA di media sosial yang dapat menimbulkan pemikiran, values, belief, dan perasaan kebencian seseorang terhadap orang-orang di luar (out-group) religius seseorang. Dari penjelasan tersebut, maka terbentuklah hipotesis untuk penelitian ini yakni terdapat hubungan positif antara keterlibatan dalam aktivitas religius seseorang dengan motivasi mengekspresikan prasangka di media sosial.

\section{Peran Ideologi Otoritarianisme dalam Hubungan Religiusitas dan Prasangka}

Alasan mengapa ideologi otoritarianisme diduga memediasi hubungan antara religiusitas dan ekspresi prasangka dapat dilihat dari beberapa penelitian sebelumnya, seperti penelitian dari Laythe, dkk. (2001). Studi ini berusaha melihat peran variabel fundamentalisme religius dan otoritarianisme terhadap prasangka. Ditemukan bahwa ideologi otoritarianisme berkorelasi kuat dengan prasangka rasial dan prasangka kepada kelompok homoseksual.
Ideologi otoritarianisme adalah ideologi yang ditunjukkan oleh seseorang yang memiliki kepatuhan tinggi pada pihak otoritas dan norma tradisional, serta menyetujui hukuman bagi orang-orang yang tidak mematuhi pihak otoritas dan norma tradisional (Stenner, 2009). Dari berbagai studi, ideologi otoritarianisme terbukti memiliki hubungan dengan prasangka terhadap outgroup yang berbeda orientasi seksual, orientasi politik, etnis, dan religius (Hathcoat \& Barnes, 2010; Turner, 2012). Penelitian lain yang memunculkan hipotesis adanya mediasi ideologi otoritarianisme dalam hubungan antara partisipasi religius dan ekspresi prasangka adalah temuan Tsang dan Rowatt (2007) yang menjelaskan bahwa ideologi otoritarianisme memediasi hubungan antara orientasi religius intrinsik dan prasangka terhadap kelompok homoseksual. Selain itu, juga terdapat penelitian yang dilakukan oleh Rowatt, LaBouff, Johnson, dan Froese (2009) yang mengungkapkan terdapat peran right-wing authoritarianism (RWA) dalam memediasi hubungan antara religiusitas dan prasangka.

Berdasarkan paparan tersebut, maka hipotesis selanjutnya untuk penelitian ini adalah ideologi otoritarianisme memediasi hubungan antara keterlibatan dalam aktivitas religius secara online dengan motivasi mengekspresikan prasangka di media sosial.

\section{Metode Penelitian}

\section{Partisipan}

Partisipan dalam penelitian ini adalah pengguna media sosial yang berusia minimal 17 tahun dan memiliki minimal satu akun media sosial. Selain itu, partisipan yang direkrut adalah partisipan beragama Islam karena pemeluk agama Islam adalah kelompok mayoritas di Indonesia. Jumlah partisipan yang berpartisipasi dalam penelitian ini adalah 152 responden yang direkrut dengan teknik insidental.

\section{Desain}

Desain penelitian yang digunakan dalam penelitian ini adalah korelasional. Variabel keterlibatan aktivitas religius secara online berperan sebagai variabel independen, sementara variabel motivasi mengekspresikan prasangka merupakan variabel dependen. Selain itu, terdapat juga variabel ideologi otoritarianisme yang berperan sebagai variabel mediator.

\section{Prosedur}

Penelitian ini menggunakan alat ukur berupa kuesioner dalam pengambilan data. Alat 
ukur dirancang dalam bentuk kuesioner online dengan pertimbangan bahwa responden yang dituju adalah pengguna media sosial. Untuk mendapatkan partisipan, peneliti menyebarkan alat ukur menggunakan pesan yang disebar melalui media online. Di awal kuesioner, tertera informed consent sebagai bagian dari prosedur etis yang dibutuhkan pada penelitian yang melibatkan manusia sebagai partisipan. Data yang sudah terkumpul kemudian diperiksa apakah dapat diolah lebih lanjut. Hanya kuesioner yang terisi lengkap dengan pola respon yang tidak repetitif yang dianalisa dalam proses selanjutnya.

\section{Alat Ukur}

Alat ukur yang digunakan dalam penelitian ini adalah alat ukur online religious engagement dari Rahman, dkk. (2015) yang terdiri dari 19 aitem untuk mengukur keterlibatan dalam aktivitas religius secara online (ORE). Sementara, untuk mengukur ideologi otoritarianisme, peneliti menggunakan alat ukur RWA sejumlah 22 aitem. Sedangkan untuk mengukur nilai internal dan eksternal untuk mengekspresikan prasangka, digunakan Motivation to Express Prejudice Scale (MEP) dari Forscher, dkk. (2015) yang terdiri dari lima aitem nilai internal (IMP) dan tujuh aitem nilai eksternal (EMP) untuk mengekspresikan prasangka. Seluruh alat ukur ini diterjemahkan ke dalam bahasa Indonesia. Khusus untuk alat ukur MEP, peneliti melakukan penyesuaian dengan karakteristik partisipan, yaitu, masyarakat Indonesia karena alat ukur MEP asli digunakan untuk mengukur ekspresi prasangka terhadap orang kulit hitam, maka aitem berbunyi orang kulit hitam dikosongkan dan ditampilkan sebagai "kelompok ___." Selain itu, untuk mengarahkan agar individu memikirkan ekspresi prasangka ini pada konteks media sosial, di dalam setiap aitem, diberikan tambahan keterangan konteks "di media sosial."

Agar responden dapat membayangkan objek prasangka ke dalam "kelompok __ " tersebut, sebelumnya, responden diminta untuk mengisi termometer perasaan. Pada termometer perasaan ini, responden diminta untuk memberikan angka 0 - 100 terhadap tujuh objek, yaitu kelompok LGBT, kelompok feminis, kelompok konservatif, kelompok liberal, kelompok pendukung pemerintah, kelompok oposan pemerintah, dan kelompok etnis Cina. Contoh aitem untuk masingmasing alat ukur ditampilkan dalam Tabel 1.

Setelah pengumpulan data, dilakukan uji reliabilitas dan dari hasil uji tersebut didapatkan hasil alpha cronbach untuk RWA adalah 0,759, EMP 0,754, IMP 0,752, dan ORE 0,872. Sehingga, dapat disimpulkan alat ukur yang digunakan dalam penelitian ini memiliki reliabilitas baik.

\section{Teknik Analisis}

Untuk menjawab pertanyaan penelitian, dilakukan beberapa aktivitas pengolahan data. Hal yang terlebih dahulu dilakukan adalah uji korelasi menggunakan korelasi pearson pada SPSS untuk menguji hipotesis 1 . Kemudian, untuk menguji hipotesis kedua, dilakukan uji mediasi dengan menggunakan software PROCESS.

\section{Hasil Penelitian}

Dari aktivitas melakukan korelasi pada variabelvariabel dalam penelitian ini, terdapat hasil yang dicantumkan dalam Tabel 2. Hasil uji hubungan menunjukkan terdapat hubungan yang signifikan dari keterlibatan terhadap aktivitas religius secara online dengan motivasi eksternal ekspresi prasangka $(r=0,165 ; p<0,05)$. Sedangkan, dari keterlibatan terhadap aktivitas religius secara online dengan motivasi internal ekspresi prasangka, tidak terdapat hubungan yang signifikan. Berdasarkan hasil tersebut, maka hanya dilakukan uji mediasi ideologi otoritarianisme terhadap hubungan keterlibatan terhadap aktivitas religius secara online dengan motivasi internal ekspresi prasangka.

Dari hasil uji mediasi, didapatkan hasil bahwa ideologi otoritarianisme dapat memediasi hubungan keterlibatan terhadap aktivitas religius secara online dengan motivasi internal ekspresi prasangka. Hasil uji tersebut digambarkan pada Gambar 1. Pertama, hasil analisis regresi dari keterlibatan religius online (variabel independen) akan ideologi otoritarianisme (variabel mediator) adalah $a=0,47, \mathrm{SE}=0,11 \%, \mathrm{t}=4.33, p<0,01$. Sumbangan efektif dari model ini $\left(\mathrm{R}^{2}\right)$ adalah 0,$11 ; \mathrm{F}(1,150)=18,77, \mathrm{p}<0,01$.

Kedua, hasil analisis regresi dari ideologi otoritarianisme (variabel mediator) pada motivasi internal ekspresi prasangka (variabel dependen) dengan memperhitungkan keterlibatan religius online (variabel independen) adalah $b=0,97$, $\mathrm{SE}=0,14 \%, \mathrm{t}=6,85, p<0,01$. Ketiga, pengaruh keseluruhan (total effect) dari keterlibatan religius online dengan motivasi internal ekspresi prasangka adalah $c=0,39, \mathrm{SE}=0,22, \mathrm{t}=1,81, p=0,07$. Keempat, pengaruh langsung (direct effect) dari keterlibatan religius online dengan motivasi internal ekspresi prasangka dengan mengontrol ideologi otoritarianisme (variabel mediator) adalah $c=0,07, \mathrm{SE}=0,21, \mathrm{t}=-0,33, p=0,74$. Model keseluruhan dari keterlibatan religius online dan ideologi otoritarianisme terhadap motivasi internal ekspresi prasangka adalah $\mathrm{R} 2=$ 0,$02 ; \mathrm{F}(2,149)=25,27, p<0,01$.

Sementara itu, analisis pada pengaruh tidak langsung (indirect effect) dari keterlibatan religius online (variabel independen) terhadap 
motivasi internal ekspresi prasangka (variabel dependen) melalui ideologi otoritarianisme (variabel mediator) menghasilkan $a b=0,46$ dan SE $=0,13$. Dengan metode bootstrapping, uji mediasi yang dilakukan mendapatkan hasil $95 \%$ biascorrected confidence interval (BCa $\mathrm{CI}$ ) berkisar antara 0,23 sampai dengan 0,74. Oleh karena angka 0 tidak tercakup dalam rentang confidence interval tersebut, maka dapat disimpulkan bahwa pengaruh tidak langsung (indirect effect) ini bersifat signifikan (tidak sama dengan 0). Dengan demikian, pengaruh keterlibatan religius online terhadap motivasi internal ekspresi prasangka diperantarai oleh ideologi otoritarianisme.

Tabel 1

Aitem alat ukur

\begin{tabular}{|c|c|c|}
\hline Variabel & Contoh aitem & Total aitem \\
\hline ORE & $\begin{array}{l}\text { - Membaca informasi tentang Islam di internet atau media sosial } \\
\text { - Melihat ceramah-ceramah agama di Youtube } \\
\text { - Mendengarkan konten islami di TV ataupun radio secara langsung (live streaming) } \\
\text { - Meminta opini atau pendapat ulama mengenai suatu permasalahan secara online } \\
\text { seperti media sosial, email, website, dll. }\end{array}$ & 19 \\
\hline EMP & $\begin{array}{l}\text { - Saya mengutarakan pemikiran negatif tentang kelompok }\left(\_ \text {_ } \text { ) di media sosial }\right. \\
\text { agar terhindar dari reaksi negatif orang lain di media sosial } \\
\text { - Saya mengurangi interaksi dengan kelompok (__ }) \text { di media sosial agar } \\
\text { terhindar dari penolakan pengguna media sosial lain } \\
\text { - Agar saya diterima dalam standar pergaulan yang ada di media sosial, saya } \\
\text { mengutarakan hal yang negatif tentang kelompok (__ di media sosial }\end{array}$ & 5 \\
\hline IMP & $\begin{array}{l}\text { - Menghindari untuk berinteraksi dengan kelompok (__ } \text { ) di media sosial adalah } \\
\text { hal yang penting untuk keyakinan diri saya } \\
\text { - Prinsip yang saya yakini memotivasi saya untuk mengungkapkan pandangan } \\
\text { negatif tentang kelompok ( } \_ \text {) di media sosial } \\
\text { - Menurut saya adalah perbuatan yang benar jika seseorang mengungkapkan } \\
\text { pemikiran positif tentang kelompok (_ }\end{array}$ & 7 \\
\hline RWA & $\begin{array}{l}\text { - Negara kita begitu membutuhkan pemimpin kuat untuk menghancurkan pola } \\
\text { hidup penuh kebebasan dan banyak dosa yang dapat menghancurkan bangsa } \\
\text { - Para ateis dan orang yang suka memberontak terhadap ajaran agama adalah orang } \\
\text { baik dan bermoral, sama dengan orang yang hadir ke tempat ibadah secara rutin } \\
\text { - Negara kita butuh pemikir bebas yang berani menantang nilai tradisional, walau } \\
\text { orang seperti ini mengesalkan banyak orang } \\
\text { - Negara kita akan hancur suatu hari jika kita tidak melenyapkan kegiatan } \\
\text { penyimpangan moral dan pelanggaran nilai tradisional }\end{array}$ & 22 \\
\hline
\end{tabular}

\section{Gambar 1}

Efek mediasi dari Ideologi Otoritarianisme (RWA) dalam hubungan Keterlibatan Religius Online (ORE) dan Motivasi Internal Ekspresi Prasangka (IMP)

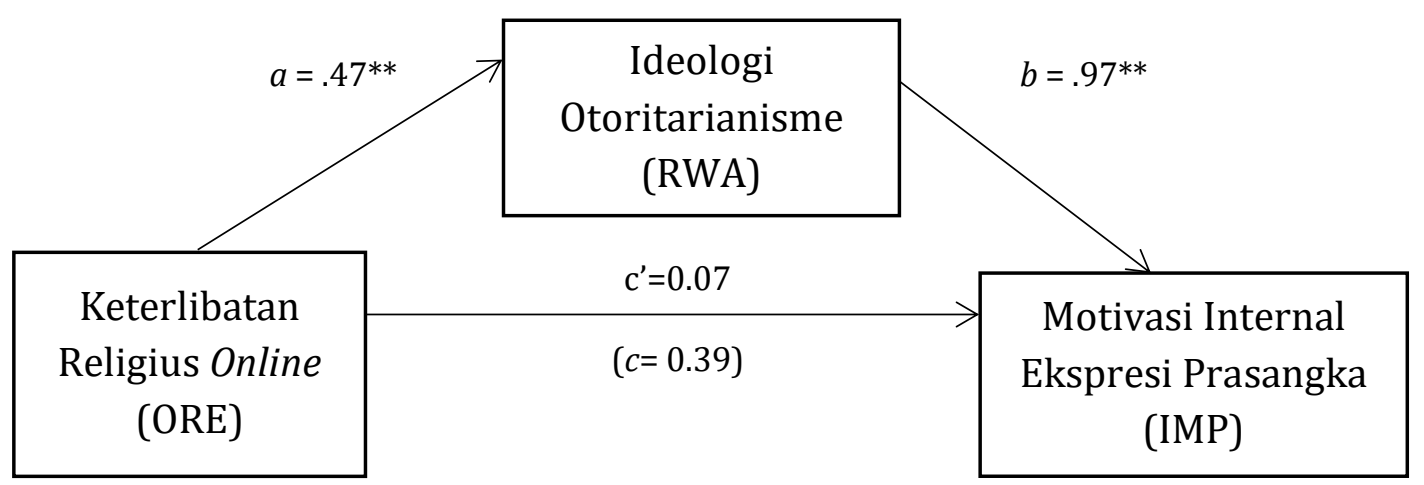

Ket: ${ }^{* *} \mathrm{p}<.01 ; a$ adalah pengaruh dari ORE terhadap RWA; $b$ adalah pengaruh dari RWA terhadap IMP; $c$ adalah pengaruh keseluruhan dari ORE terhadap IMP; c' adalah pengaruh langsung dari ORE terhadap IMP 
Tabel 2

Uji korelasi

\begin{tabular}{|c|c|c|c|c|c|c|}
\hline & Mean & SD & 1 & 2 & 3 & 4 \\
\hline 1. Ideologi Otoritarianisme (RWA) & 6,088 & 0,844 & 1 & & & \\
\hline $\begin{array}{l}\text { 2. Motivasi Eksternal Ekspresi } \\
\text { Prasangka (EMP) }\end{array}$ & 4,360 & 1,836 &, $181^{*}$ & 1 & & \\
\hline $\begin{array}{l}\text { 3. Motivasi Internal Ekspresi } \\
\text { Prasangka (IMP) }\end{array}$ & 5,373 & 1,598 &, $503^{* *}$ &, $427^{* *}$ & 1 & \\
\hline $\begin{array}{l}\text { 4. Online Religious Engagement } \\
\text { (ORE) }\end{array}$ & 2,676 & 0,590 &, $333^{* *}$ &, $165^{*}$ & ,146 & 1 \\
\hline
\end{tabular}

*Korelasi signifikan pada level 0,05

**korelasi signifikan pada level 0,01

\section{Diskusi}

Dari hasi uji hubungan dapat terlihat bahwa terdapat korelasi antara keterlibatan terhadap aktivitas religius secara online dengan motivasi eksternal ekspresi prasangka. Hubungan ini dapat terjadi karena, ketika seseorang berpartisipasi dalam aktivitas religius di dunia maya, seperti misalnya mencari informasi agama, maka terdapat kemungkinan seseorang akan berinteraksi dengan komunitas religius di dunia maya yang memiliki kesamaan nilai religius. Hal ini dijelaskan oleh teori identitas sosial dari Tajfel dan Turner (2010), yang menjelaskan bahwa seseorang dapat tergabung dalam kelompok sosial yang memiliki atau meyakini kesamaan emosi dan values yang dianggap penting. Lebih lanjut, Graham dan Haidt (2010) menekankan bahwa agama membuat seseorang terikat dengan komunitas moral.

Saat berinteraksi dengan komunitas religius, seseorang dapat mengembangkan identitas religius dan mengadopsi nilai, pemikiran, atau belief dari komunitasnya. Dalam hal bila komunitas religius yang diikuti seseorang menanamkan atau menunjukkan bahwa ekspresi prasangka terhadap out-group adalah sesuatu yang wajar, maka seseorang dapat merujuk kepada norma tersebut untuk turut mengekspresikan prasangka yang dimilikinya. Menurut Hood Jr., Hill, dan Williamson (2005), beberapa komunitas religius menekankan bahwa hanya ada satu ajaran yang benar (ortodoxy), dan karena itu berinteraksi dengan orang yang memiliki agama yang berbeda (religious out-group) dapat melemahkan keyakinan beragama yang seseorang miliki. Hal ini juga dapat menyebabkan seseorang berpikir bahwa religious out-group membawa ancaman (threatening religiosity) dan karena itu menganggap berinteraksi dengan religious out-group perlu dihindari. Perasaan terancam ini juga dapat dijelaskan oleh teori integrated threat (Stephan \& Renfro, 2002) yang menjelaskan prasangka akan muncul jika komunitas religius menggambarkan religious out-group berkompetisi dengan komunitas religius (religious in-group) memperebutkan materi- materi fisik yang dimiliki oleh pemeluk agama (misalnya tempat ibadah atau tempat yang dianggap suci). Penelitian Kossowska, Szwed, Kukuczka, Sekerdej, dan Wyczesany (2017) lebih lanjut menjelaskan bahwa individu yang sangat ortodoks lebih mudah merasa terancam oleh religious out-group dibandingkan mereka yang non-ortodoks. Cara yang dapat dilakukan untuk mengurangi perasaan terancam dan menimbulkan perasaan lega adalah dengan mengekspresikan prasangka.

Penjelasan selanjutnya mengapa terdapat hubungan antara keterlibatan dalam aktivitas religius secara online dengan motivasi mengekspresikan prasangka adalah tipe paparan informasi agama (religious priming) yang lebih banyak diakses individu. Penelitian Johnson (2017) menjelaskan bahwa religious priming terdiri dari priming good supranatural agents dan priming evil supranatural agents di mana individu yang sering mendengar atau mendapatkan informasi terkait hukuman di dalam ajaran agama (priming evil supranatural agents) akan memiliki agresivitas yang lebih rendah dibanding mereka yang lebih banyak terpapar dengan materi agama tentang balasan menyenangkan bagi perilaku baik (priming good supranatural agents). Serupa dengan hal ini, penelitian Clobert, Saroglou, Hwang, dan Soong (2014) juga menunjukkan bahwa menampilkan priming tentang gambaran biksu Buddha yang sedang bermeditasi dapat menurunkan tingkat prasangka implisit kepada outgroup etnis. Menurut Preston, Ritter, dan Ivan Hernandez (2010), priming materi religius yang dilakukan secara subliminal maupun secara supraliminal dapat mengaktivasi jaringan syaraf yang dapat memengaruhi pemrosesan kognitif dan afektif individu, termasuk meningkatkan prasangka. Dengan demikian, penelitian-penelitian ini menunjukkan bahwa ketika individu terlibat dalam aktivitas religius di dunia maya, seperti mencari informasi agama, maka tipe informasi agama tertentu yang banyak diakses oleh individu tersebut dapat membentuk prasangka melalui aktivitasi proses kognitif dan afektif individu. 
Dari hasil uji mediasi, didapatkan hasil bahwa variabel ideologi otoritarianisme memediasi hubungan antara keterlibatan dalam aktivitas religius secara online dengan nilai internal ekspresi prasangka. Hal ini juga ditunjukkan oleh korelasi positif antara partisipasi religius dengan ideologi otoritarianisme, adanya korelasi positif antara ideologi otoritarianisme dengan motivasi internal ekspresi prasangka, dan tidak adanya korelasi positif antara partisipasi religius dengan motivasi internal ekspresi prasangka.

Individu dengan ideologi otoritarianisme yang tinggi memiliki derajat kepatuhan yang tinggi terhadap aturan konvensional yang sesuai dengan nilai internal yang diyakininya (Duckitt, 2006), atau dengan kata lain seseorang dengan ideologi otoritarianisme yang tinggi, sangat konservatif. Hubungan signifikan antara partisipasi religius dengan ideologi otoritarianisme dijelaskan oleh penelitian sebelumnya yang mengatakan bahwa semakin religius seseorang maka semakin besar penghormatannya terhadap tradisi (Saroglou, Delpierre, \& Dernelle, 2004), serta pilihan politiknya juga semakin konservatif (Norris \& Inglehart, 2004). Dapat disimpulkan bahwa seseorang yang tinggi keterlibatannya dalam aktivitas religius, maka hal itu membuat seseorang makin konservatif atau makin memiliki ciri otoritarianisme.

Sedangkan, hubungan antara ideologi otoritarianisme dengan motivasi internal ekspresi prasangka disebabkan seseorang dengan ideologi otoritarianisme yang tinggi merasakan bahwa nilai yang dianutnya adalah nilai yang paling benar dan melihat bahwa out-group memiliki nilai yang salah (Altemeyer \& Hunsberger, 1992). Hal ini menyebabkan seseorang dengan ideologi otoritarianisme yang tinggi lebih termotivasi secara internal untuk mengekspresikan prasangka.

Dengan demikian, hasil dari penelitian ini menyatakan bahwa ideologi otoritarianisme memediasi partisipasi religius dengan motivasi internal ekspresi prasangka. Hasil studi ini konsisten dengan penelitian Newheiser, Hewstone, Voci, Schmid, Zick, dan Küpper (2013) yang menjelaskan bahwa right-wing authoritarianism berperan sebagai variabel mediator dalam hubungan antara agama dan prasangka rasial. Hubungan antara ketiga variabel tersebut juga tergambar dari penelitian Shackelford dan Besser (2007) yang melihat bahwa semakin tua usia individu, maka ia cenderung semakin konservatif, semakin memiliki fundamentalisme dalam beragama, dan semakin negatif sikapnya terhadap perilaku homoseksual.

\section{Kesimpulan}

Pada penelitian ini, dapat disimpulkan bahwa semakin tinggi partisipasi religius seseorang di media sosial, maka semakin mungkin seseorang tersebut terpengaruh oleh lingkungan sosial yang mengekspresikan prasangka terhadap kelompok di luar kelompok religius mereka. Hubungan ini dapat terjadi apabila individu mengembangkan identitas sosial yang kuat terhadap komunitas religiusnya dan merasakan identitas keberagamaannya terancam akibat bentuk priming materi agama yang mendukung ekspresi prasangka dari komunitas religiusnya. Selain itu, seseorang dengan partisipasi religius yang tinggi tidak semerta-merta mengadopsi nilai dalam diri untuk mengekspresikan prasangka. Akan tetapi, nilai tersebut akan terbentuk jika seseorang mengembangkan ideologi konservatif atau pemikiran bahwa nilai yang dianutnya adalah nilai yang paling benar dan menganggap bahwa nilai yang dianut orang lain yang tidak sejalan dengan dirinya adalah salah, serta menganut pemahaman bahwa mendiskriminasi orang yang menganut nilai yang berbeda dengannya adalah diperbolehkan.

Namun demikian, penelitian ini tidak dapat menjelaskan lebih lanjut apakah terdapat perbedaan ekspresi prasangka terhadap kelompok out-group yang berbeda sebagai akibat dari religiusitas. Berdasarkan penelusuran literatur sebelumnya, sangat mungkin bahwa pengaruh religiusitas terhadap ekspresi prasangka dapat berbeda dengan hasil yang didapat dari penelitian ini. Hal ini dapat terjadi karena menurut penelitian sebelumnya, terdapat kelompok-kelompok tertentu yang dianggap lebih pantas menerima diskriminasi (seperti kelompok LGBT dan kelompok atheis) oleh komunitas religius dibandingkan kelompok yang berbeda agama atau kelompok berbeda ras. Oleh karena itu, penelitian selanjutnya dapat mempertimbangkan untuk meneliti ekspresi prasangka komunitas religius pada kelompok-kelompok berdasarkan orientasi seksual, ras, dan berbeda agama.

Implikasi praktis dari penelitian ini antara lain adalah perlunya tokoh dan pemuka agama untuk menekankan materi agama yang lebih menekankan nilai-nilai kemanusiaan dan pentingnya memiliki akhlak yang baik terhadap semua manusia dibandingkan materi agama yang justru menajamkan jarak sosial antar pemeluk agama yang berbeda. 


\section{Daftar Pustaka}

Altemeyer, B., Hunsberger, B. (1992). Authoritarianism, religious fundamentalism, quest, and prejudice. The International Journal for The Psychology of Religion.

https://doi.org/10.1207/s15327582ijpr0 202_5

Bilewicz, M., Soral, W., Marchlewska, M., \& Winiewski, M. (2017). When authoritarians confront prejudice. differential effects of sdo and rwa on support for hate-speech prohibition. Political Psychology. https://doi.org/10.1111/pops.12313

Brambilla, M., Manzi, C., Regalia, C., Verkuyten, M. (2013). Religiosity and prejudice: Different patterns for two types of religious internalization. Journal of Social Psychology, 153(4), 486-498. https://doi.org/10.1080/00224545.2013. 768592

Burch-Brown, J., Baker, W. (2016). Religion and reducing prejudice. Group Processes and Intergroup Relations. https://doi.org/10.1177/1368430216629 566

Clobert, M., Saroglou, V., Hwang, K. K., \& Soong, W. L. (2014). East Asian religious tolerance-A myth or a reality? Empirical investigations of religious prejudice in East Asian societies. Journal of Cross-Cultural Psychology.

https://doi.org/10.1177/0022022114546 641

Crandall, C. S., Eshleman, A. (2004). The justification-suppression model of prejudice: An approach to the history of prejudice research. Social Psychology of Prejudice: Historical and Contemporary Issues, 237-268.

Duckitt, J. (2006). Differential effects of right wing authoritarianism and social dominance orientation on outgroup attitudes and their mediation by threat and competitiveness to outgroups. Personality and Social Psychology Bulletin, 32, 684-696.

Forscher, P. S., Cox, W. T. L., Graetz, N., Devine, P. G. (2015). The motivation to express prejudice. Journal of Personality and Social Psychology. https://doi.org/10.1037/pspi0000030

Graham, J., Haidt, J. (2010). Beyond beliefs: Religions bind individuals into moral communities. Personality and Social Psychology Review. https://doi.org/10.1177/1088868309353 415

Hall, N. (2013). Hate crime. Abingdon: Routledge.
Hathcoat, J. D., Barnes, L. L. B. B. (2010). Explaining the relationship among fundamentalism and authoritarianism: An epistemic connection. International Journal for the Psychology of Religion. https://doi.org/10.1080/1050861100360 7884

Hoffarth, M. R., Hodson, G., Molnar, D. S. (2018). When and why is religious attendance associated with antigay bias and gay rights opposition? A justification-suppression model approach. Journal of Personality and Social Psychology. https://doi.org/10.1037/pspp0000146

JakartaPost. (2017). Hate speech clouds Indonesia's internet in 2016: Police. Diakses melalui http://www.thejakartapost.com/news/20 17/03/26/hate-speech-clouds-indonesiasinternet-in-2016-police.html

Johnson, C. L. (2017). The impact of priming different aspects of religion on aggressive behavior. ProQuest Dissertations and Theses. Diakses melalui https://pqdtopen.proquest.com/pubnum/ 10253949.html

Johnson, M. K., Rowatt, W. C., LaBouff, J. (2010). Priming Christian Religious Concepts Increases Racial prejudice. Social Psychological and Personality Science. https://doi.org/10.1177/1948550609357 246

Johnson, M. K., Rowatt, W. C., Labouff, J. P. (2012). Religiosity and prejudice revisited: Ingroup favoritism, out-group derogation, or both? Psychology of Religion and Spirituality. https://doi.org/10.1037/a0025107

Kossowska, M., Szwed, P., CzernatowiczKukuczka, A., Sekerdej, M., Wyczesany, M. (2017). From threat to relief: Expressing prejudice toward Atheists as a Selfregulatory strategy protecting the religious Orthodox from threat. Frontiers in $\begin{array}{lrr}\text { Psychology, } & 8, & 873 .\end{array}$ https://doi.org/10.3389/fpsyg.2017.0087 3

Laythe, B., Finkel, D., \& Kirkpatrick, L. A. (2001). Predicting prejudice from religious fundamentalism and right-wing authoritarianism: A multiple-regression approach. Journal for the Scientific Study of Religion, 40(1), 1-10. https://doi.org/10.1111/00218294.00033

Newheiser, A., Hewstone, M., Voci, A., Schmid, K., Zick, A. Küpper, B. (2013). Socialpsychological aspects of religion and prejudice: Evidence from survey and 
experimental research. In J. Clarke, S., Powell, R. \& Savulescu (Ed.), Religion, intolerance, and conflict: A scientific and conceptual investigation (pp. 107-125). Oxford: Oxford University Press. https://doi.org/10.1093/acprof:oso/9780 199640911.003 .0006$.

Norris, P., Inglehart, R. (2004). Sacred and Secular: Religion and Politics Worldwide. Cambridge University Press.

Pasek, M. H., Cook, J. E. (2017). Religion from the target's perspective. Social Psychological and Personality Science, 10(1), 82-93. https://doi.org/https://doi.org/10.1177/ 1948550617739089

Pew Research Center. (2014). Religion and electronic media. Diakses melalui https://www.pewforum.org/2014/11/06 /religion-and-electronic-media/

Preston, J. L., Ritter, R. S., Ivan Hernandez, J. (2010). Principles of religious prosociality: A review and reformulation. Social and Personality Psychology Compass. https://doi.org/10.1111/j.17519004.2010.00286.x

Rahman, A. A., Hashim, N. H., Mustafa, H. (2015). Muslims in cyberspace: Exploring factors influencing online religious engagements in Malaysia. Media Asia. https://doi.org/10.1080/01296612.2015. 1072343

Hood Jr., R. W., Hill, P. C., Williamson, W. P. (2005). The psychology of religious fundamentalism. New York: Guilford Press.

Ramsay, J. E., Pang, J. S., Shen, M. J., Rowatt, W. C. (2013). Rethinking value violation: Priming religion increases prejudice in Singaporean Christians and Buddhists. The International Journal for the Psychology of Religion, 24(1), 1-15. Diakses melalui https://www.tandfonline.com/doi/abs/10 .1080/10508619.2012.761525?journalCo de=hjpr20

Rowatt W. C., LaBouff J., Johnson M. K., Froese P., T. J. (2009). Associations among religiousness, social attitudes, and prejudice in a national random sample of American adults. Psychology of Religion and Spirituality, $1, \quad 14-24$. https://doi.org/10.1037/a0014989

Saroglou, V., Delpierre, V., Dernelle, R. (2004). Values and religiosity: A meta-analysis of studies using Schwartz's model. Personality and Individual Differences. https://doi.org/10.1016/j.paid.2003.10.0 05

Shackelford, T. K., Besser, A. (2007). Predicting attitudes toward homosexuality: Insights from personality psychology. Individual Differences Research

Stenner, K. (2009). Three kinds of "Conservatism." Psychological Inquiry, 20(2-3), 142-159. https://doi.org/10.1080/1047840090302 8615

Stephan, W. G., Renfro, C. L. (2002). The role of threats in intergroup relations. In D. Mackie \& \& E. R. Smith (Eds.), From prejudice to intergroup emotions (pp. 191-208). New York: Psychology Press.

Tajfel, H., \& Turner, J. C. (2010). An integrative theory of intergroup conflict. In T. Postmes \& N. R. Branscombe (Eds.), Key readings in social psychology. Rediscovering social identity (p. 173-190). Psychology Press.

Tsang, J.-A., Rowatt, W. C. (2007). The relationship between religious orientation, right-wing authoritarianism, and implicit sexual prejudice. The International Journal for the Psychology of Religion, 17(2), 99120.

https://doi.org/10.1080/1050861070124 4122

Turner, D. (2012). Racial prejudice, homophobia, and sexism as a function of right-wing authoritarianism, religious values, religious pressures, and religious orientation. Dissertation Abstracts International: Section B: The Sciences and Engineering.

Yar, M. (2013). Cyber Crime and Society. London: Sage. 